\title{
DETECTION OF ANTIBODIES TO SENDAI VIRUS BY ENZYME-LINKED IMMUNOSORBENT ASSAY (ELISA)
}

\author{
H.C.J. ERTL *, W. GERLICH and U.H. KOSZINOWSKI ** \\ Hygiene-Institut der Universität Göttingen, Lehrstuhl Medizinische Mikrobiologie, \\ Kreuzbergring 57,D-34 Göttingen, G.F.R.
}

(Received 6 November 1978, accepted 6 December 1978)

An enzyme-linked immunosorbent assay (ELISA) for the detection of antibodies to Sendai virus, a paramyxovirus, is described. The assay was found to be about 20 -fold more sensitive than the hemagglutination inhibition assay. Differentiation between virus specific IgG and IgM is possible. The test appears to be especially useful in the study of early events in antibody formation in vivo as well as in vitro.

\section{INTRODUCTION}

Viruses induce cellular and humoral immune responses in the host. This dichotomy is governed by principles not yet fully understood. In cellular immune responses the major histocompatibility complex (MHC) is of importance at the level of T-cell differentiation (Bennink and Doherty, 1978) as well as of T-effector cell function (Doherty et al., 1976). The degree of MHC restricted antiviral responses has been shown to be under the control of immune response genes (Doherty et al., 1978). It is not yet known to what extent the antiviral antibody response is regulated by immune response genes. Since the induction of antibody formation against various protein antigens is under T-helper cell control (Roberts et al., 1975) it is to be

\footnotetext{
* Present address: John Curtis School of Medical Research, Microbiology Department, The Australian National University, Post Office Box 4, Canberra, ACT 2600, Australia. ** Deutsches Krebsforschungszentrum, Institut für Immunologie und Genetik, Im Neuenheimer Feld 280, D-69 Heidelberg, G.F.R.

List of abbreviations: BSA, bovine serum albumin; CF, chorioallantoic fluid; ChHC, chicken host components; ELISA, enzyme-linked immunosorbent assay; FCS, fetal calf serum; HAU, hemagglutinating units; HAIU, hemagglutination inhibition units; HIA, hemagglutination inhibition assay; HRPO, horse radish peroxidase; i.n., intranasal; i.p., intraperitoneal; i.v., intravenous; $M$, molar; $A$, absorbance; PBS, phosphate buffered saline; RAM/Ig, rabbit anti-mouse-Ig; RAM/IgG, rabbit anti-mouse-IgG; RAM/IgM, rabbit anti-mouse-IgM (Fc); RIA, radioimmunoassay; T-cells, thymus derived cells; TCID $_{50}$, $50 \%$ tissue culture infective doses; s.c., subcutaneous; SV, Sendai virus; w/v, weight per volume.
} 
expected that regulatory functions of T cells govern the production of antibodies as well.

The analysis of antibody response to viral antigens requires sensitive tests. Virus neutralisation assay is very sensitive (Svenag and Mandel, 1964), but it is too laborious to use as a routine method. Complement binding is not sensitive enough. The hemagglutination inhibition assay is also not sufficiently sensitive and is furthermore restricted to antibodies to hemagglutinin. Furthermore the conventional tests are not able to discriminate between different classes of immunoglobulins and the antibody level is difficult to quantify.

'This report describes different modifications of the enzyme-linked immunosorbent assay for the detection of antibodies to Sendai virus. The assays allow the demonstration of low levels of antibodies very early after sensitization and the differentiation between IgG and IgM. Small differences in antibody levels can be detected and the sensitivity of the assays allows the investigation of antibodies produced by cells in a primary in vitro induction phase.

\section{MATERIALS AND METHODS}

\section{Mice}

Adult male and female C3H/TIF and DRA/2 inbred mice (Bornholdgard, Ry, Denmark) were used at $8-12$ weeks of age.

\section{Viruses}

Sendai virus was grown in the chorioallantoic fluid of 10-day-old embryonated hen eggs for $44-48 \mathrm{~h}$ at $37^{\circ} \mathrm{C}$.

Influenza virus $\mathrm{A}$, strain Victoria, was grown in the chorioallantoic fluid of 11-day-old embryonated hen eggs for $40-44 \mathrm{~h}$ at $37^{\circ} \mathrm{C}$.

Hemagglutination titration was carried out by Salk's pattern method (Salk, 1944) using $0.2 \%$ chicken red blood cells. Purification of Sendai virus was done by centrifugation of the virus-containing chorioallantoic fluid at $3000 \mathrm{rev} . / \mathrm{min}$ for $30 \mathrm{~min}$ to remove cell debris and chicken red blood cells. The supernatant was layered on $10 \mathrm{ml} 60 \%$ sucrose $(\mathrm{w} / \mathrm{v})$ and centrifuged for $90 \mathrm{~min}$ at $20,000 \times \mathrm{g}$ ( $\mathrm{SW}-27$ rotor, Beckmann). The virus layer was collected and purified by a linear sucrose gradient from $10 \%$ to $60 \%(\mathrm{w} / \mathrm{v})$ centrifugation for $90 \mathrm{~min}$ at $20,000 \times g$ (SW-50.1 rotor, Beckmann). The visible virus layer was removed and dialysed against phosphate buffered saline overnight. Aliquots of purified or unpurified Sendai virus were stored at $-70^{\circ} \mathrm{C}$.

Protein content of the purified virus was determined by the method of Lowry et al. (1951).

Inactivation of Sendai virus was carried out by treatment with $\beta$-propiolactone for $18 \mathrm{~h}$ at a concentration of $0.025 \%$ (Koszinowski et al., 1977b).

Vaccinia virus, strain WR, was propagated in Vero cells (monkey kidney cells) as described oarlior (Koszinowski and Thomssen, 1975). 


\section{Antisera}

Sendai virus (50--100 hemagglutinating units of umpurified, or $500 \mathrm{ng}$ of purified, inactivated virus) was injected intraperitoneally, intravenously, subcutaneously or intranasally. Booster injections were carried out in weekly intervals. Mice were bled by retro-orbital puncture. Immediately before infection, sera were taken for controls.

Antisera to influenza virus were obtained by i.p. injection of 50-100 hemagglutinating units.

Titers of antisera to Sendai or influenza virus were determined in a hemagglutination inhibition assay as described earlier (Ertl and Koszinowski, 1977).

Vaccinia virus antisera were prepared by i.p. injection of $1 \times 10^{5} \mathrm{TCID}_{50}$ vaccinia virus. Titers were measured in a complement-dependent ${ }^{51} \mathrm{Cr}$-release assay, using vaccinia virus infected L-929 cells as targets (Koszinowski et al., 1977a). The serum used in this report had a titer of 1: 4048.

Antiserum to rubella virus was kindly provided by Prof. R. Thomssen.

Antisera to chorioallantoic fluid were prepared by i.p. injection of $1 \mathrm{ml}$ chorioallantoic fluid of 12-day-old embryonated hen eggs.

Antisera to mouse- $\gamma$-globulin from rabbit (RAM/Ig) were obtained from Behringwerke, Marburg/Lahn, G.F.R.

Antisera to mouse-IgG (RAM/IgG) and mouse-IgM (RAM/IgM) from rabbit were obtained from Nordic Immunological Laboratories, Tilburg, The Netherlands.

\section{Purification of $\operatorname{Ig} G$}

One millilitre of antiserum was dialysed for $2 \mathrm{~h}$ against $0.02 \mathrm{M}$ phosphate buffer, $\mathrm{pH} 8.0$, and then added to a chromatography column of $20 \mathrm{~cm} \times 0.5$ $\mathrm{cm}$ diethylaminoethylcellulose (DEAE-Sephacel, lot No. 1482, Pharmacia, Fine Chemicals AB, Uppsala, Sweden). IgG was eluated with $0.02 \mathrm{M}$ phosphate buffer, $\mathrm{pH}$ 8.0. Twelve to sixteen $1 \mathrm{ml}$ fractions were collected, and the protein content was estimated by optical density at $280 \mathrm{~nm}$. The four peak fractions were collected and used for further assays.

\section{Preparation of conjugates}

Antisera and purified Sendai virus were labeled with horse radish peroxidase (HRPO, Type VI, Prod. No. p-8375, Sigma Chemical Co., St. Louis) by a combination of the methods of Nakane (1975) and Avrameas and Ternynk (1971). Briefly, $20 \mathrm{mg}$ HRPO were dissolved in $1 \mathrm{ml}$ of $0.3 \mathrm{M}$ sodium bicarbonate buffer, $\mathrm{pH} 8.4$. Then $0.3 \mathrm{ml}$ of $25 \%$ glutaraldehyde (Serva, Heidelberg) was added for $30 \mathrm{~min}$ at room temperature. To remove excess glutaraldehyde the solution was applied to a $5.0 \times 1.0$ Sephadex G-25 M column (Column PD-10, Pharmacia, Fine Chemicals, Uppsala, Sweden) in $0.3 \mathrm{M}$ sodium bicarbonate buffer, $\mathrm{pH}$ 8.0. The eluated enzyme was incubated with $0.5 \mathrm{ml}$ of $0.1 \mathrm{M} \mathrm{NaIO}_{4}$ for $30 \mathrm{~min}$ at room temperature. Then $0.1 \mathrm{ml}$ of ethylene glycol was added for $10 \mathrm{~min}$ at room temperature. The solution was 
applied to a Sephadex PD-10 column in 0.01 M sodium bicarbonate buffer, $\mathrm{pH}$ 9.5. The activated peroxidase was used for labeling proteins within the next four hours.

Labeling of Sendai virus or antisera: $10 \mathrm{mg}$ of IgG in $1 \mathrm{ml}$ buffer or $4 \mathrm{mg}$

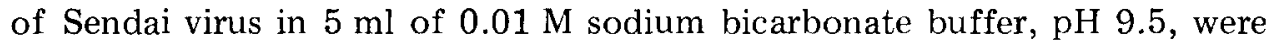
added to $20 \mathrm{mg}$ of activated peroxidase. The solution was stirred for $2 \mathrm{~h}$ at room temperature. After cooling to $4^{\circ} \mathrm{C}, 5 \mathrm{mg}$ solid $\mathrm{NaBH}_{4}$ were added and the solution left at $4^{\circ} \mathrm{C}$ for $2 \mathrm{~h}$. The solution was then dialysed at $4^{\circ} \mathrm{C}$ for $24 \mathrm{~h}$.

Purification of labeled Sendai virus from free HRPO was by 2 -fold linear sucrose gradient $(10 \%$ to $60 \% \mathrm{w} / \mathrm{v})$ centrifugation for $90 \mathrm{~min}$ at $20,000 \times \mathrm{g}$ (SW 50.1 rotor, Beckmann). To separate conjugated IgG from free HRPO, the samples were applied to a $100 \mathrm{~cm} \times 1.6 \mathrm{~cm}$ Biogel P-300 column in $0.02 \mathrm{M}$ Tris-HCl, $0.13 \mathrm{M} \mathrm{NaCl}$ buffer, $\mathrm{pH}$ 7.4. Fractions of $1 \mathrm{ml}$ were collected and optical density was measured at $280 \mathrm{~nm}$ and $403 \mathrm{~nm}$. RZ values $\left(A_{403} / A_{280}\right)$ were calculated. Fractions with $\mathrm{RZ}$ values of 0.5 to 0.7 were collected and used in the further assays.

\section{Enzyme linked immunosorbent assay (ELISA)}

Wells of flexible polyvinyl microtiter plates (M 24, Cooke Laboratory) were coated with $200 \mathrm{ng}$ purified Sendai virus or with a $1: 200$ dilution of $\mathrm{RAM} / \mathrm{IgM}$ suspended in a volume of $100 \mu 1,0.02 \mathrm{M}$ phosphate buffer, $\mathrm{pH} 7.4$, for $18-24 \mathrm{~h}$ in a sealed humidified plastic box at $4^{\circ} \mathrm{C}$. Control wells were coated with chicken chorioallantoic fluid $1: 10$ diluted in phosphate buffer or merely with buffer. After rinsing $(3 \times 2 \mathrm{~min}$ with $0.02 \mathrm{M}$ phosphate buffer, $\mathrm{pH} 7.4$ ) the wells were filled with $150 \mu \mathrm{l}$ normal guinea pig serum for $2 \mathrm{~h}$. After another rinsing step, $100 \mu \mathrm{l}$ of test serum or negative control serum were added and the plates left for 20-30 min at room temperature. Control wells were filled with buffer instead of serum. After a further 3 -fold rinsing, $100 \mu \mathrm{l}$ of conjugate containing 50-200 $\mathrm{ng}$ of SV-HRPO or $100 \mathrm{ng}$ of labeled anti-mouse- $\gamma$-globulin IgG (RAM/Ig, RAM/IgG or RAM/IgM) diluted in buffer containing $2 \% \mathrm{BSA}$, were incubated for $20-30 \mathrm{~min}$ at room temperature. After 3-fold rinsing $100 \mu \mathrm{l}$ of freshly prepared substrate (orthophenylenediamine $0.4 \mathrm{mg} / \mathrm{ml}+0.006 \% \mathrm{H}_{2} \mathrm{O}_{2}$ in $0.1 \mathrm{M}$ citrate buffer, pH 5.0) was added and the plates incubated in the dark at room temperature. After $30 \mathrm{~min}, 50 \mu \mathrm{l} 2 \mathrm{M}$ sulfuric acid were added to each well to stop the enzyme reaction and the absorbance was measured at $493 \mathrm{~nm}$. A solution of $100 \mu \mathrm{l}$ of substrate and $50 \mu \mathrm{l}$ of sulfuric acid was taken as blank. Absorbance was measured in disposable cuvettes, 1 to 2.5 diluted in $5 \% \mathrm{Na}_{2} \mathrm{SO}_{4}$. The experimental schedule is shown in Fig. 1.

\section{Primary induction of antibody formation in vitro}

$1 \times 10^{8}$ viable spleen lymphocytes $/ \mathrm{ml}$ of $\mathrm{DBA} / 2$ mice were cultured in 25 ml RPMI 1640 medium (Grand Island Biological Co., N.Y.) supplemented with $10 \%$ FCS (fetal calf serum), antibiotics, $2 \times 10^{-5} \mathrm{M} 2$-mercaptoethanol 


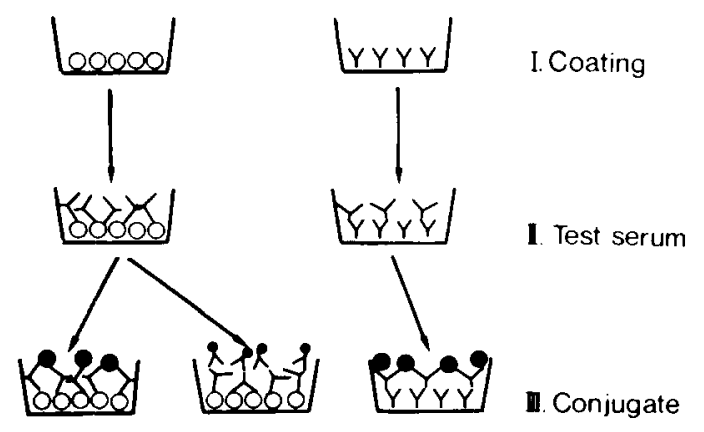

$\begin{array}{ll}\text { OSendai virus } & \text { Y RAM } / \mathrm{lgM} \\ \text { Y test serum } & \\ \text { - SV-HRPO } & \lambda \text { RAM/lg-HRPO }\end{array}$

Fig. 1. Principle of different ELISA techniques. I. Coating with SV or RAM/IgM (18$24 \mathrm{~h}$ ). II. After 3 -fold rinsing, normal guinea pig serum was incubated in the wells for $2 \mathrm{~h}$ and rinsed out. The test serum was then added and incubated at RT for $20-30 \mathrm{~min}$. III. After 3 -fold rinsing SV-HRPO or enzyme-labeled $\mathrm{RAM} / \mathrm{Ig}, \mathrm{RAM} / \mathrm{IgG}$ or RAM/IgM was added for 20-30 min. Orthiphenylenediamine and $\mathrm{H}_{2} \mathrm{O}_{2}$ were used as substrate.

and $1 \%$ glutamine with $100 \mathrm{ng} \beta$-propiolactone inactivated Sendai virus $/ \mathrm{ml}$ for 4 days at $37^{\circ} \mathrm{C}$ in a humidified atmosphere with $5 \% \mathrm{CO}_{2}$. After 3-fold washings the cells were resuspended in a serum free medium for another 2 days. Control cells were cultured under the same conditions in a virus free medium. Supernatants were collected and freeze-dried.

\section{RESULTS}

\section{Test requirements}

Coating conditions. The sensitivity of ELISA depends on the concentration of Sendai virus or RAM/IgM used for coating of wells (Fig. 2). High concentrations of antigen and a $10^{-2}$ to $10^{-3}$ dilution of RAM/IgM were found to give best results. For further assays $200 \mathrm{ng} \mathrm{SV} /$ well or a $1: 200$ dilution of $\mathrm{RAM} / \mathrm{IgM}$ were used.

Coating procedure of SV or R AM/IgM is time-dependent. Maximal values of specific binding were obtained if the assay was done about $24 \mathrm{~h}$ after coating of wells with SV or RAM/IgM. Coating for a time exceeding $48 \mathrm{~h}$ resulted in loss of activity probably due to antigen degradation in the case of virus or to a loss of binding of proteins to the plastic wells.

Coating procedure is independent from temperature. Wells coated with SV or $\mathrm{RAM} / \mathrm{IgM}$ at $4^{\circ} \mathrm{C}, 22^{\circ} \mathrm{C}$ or $37^{\circ} \mathrm{C}$ showed nearly identical results. To 


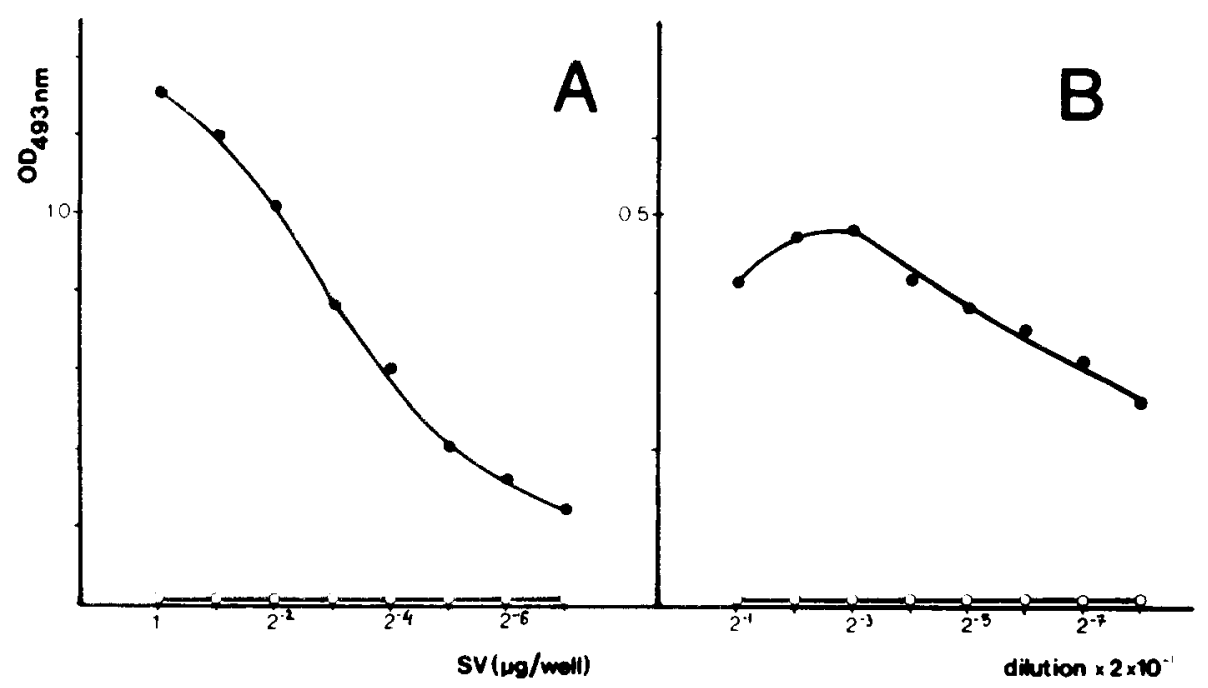

Fig. 2. Coating concentration of SV or RAM/IgM. Wells were coated with different concentrations of SV (A) or RAM/IgM (B). (•——) serum of DBA/2 mice, 1 week after infection with $100 \mathrm{HAU}$ SV (serum No. 13.1); (O- O) Pre-infection serum (serum No. 13.0). Sera were used at a dilution of $1: 100$. SV-HRPO was used as enzyme-labeled reagent.

prevent bacterial contamination of the wells and to decrease the degradation of the temperature-sensitive viral antigens, wells were incubated at $4^{\circ} \mathrm{C}$. Within the range $\mathrm{pH} 5.0$ to $\mathrm{pH} 9.0$ there was no major difference in the coating capacity of SV or RAM/IgM. Results with wells coated at neutral pH were slightly superior to those with wells coated at basic or acid $\mathrm{pH}$. Therefore wells were usually coated in $0.02 \mathrm{M}$ phosphate buffer, $\mathrm{pH} 7.4$.

Antibody binding conditions. Immunoglobulins have a high affinity for plastic surfaces. 'Thus after the coating procedure wells were incubated with a $20 \%$ solution of guinea pig serum, which did not react with SV, mouse immunoglobulins or anti-mouse-immunoglobulin sera. This step is necessary to block non-specific adsorption of antibodies to the wells. Non-specific adsorption of antibodies to plastic wells is much slower than specific binding to a solid phase reagent. Binding of SV-antibodies to untreated wells is almost undetectable after $20 \mathrm{~min}$, whereas specific binding to SV-coated wells is complete after this time. The non-specific adsorption of mouseimmunoglobulin to SV-coated and untreated wells in comparison to specific binding of SV-antibodies is shown in Fig. 3. Coating wells with SV seems to inhibit the unspecific adsorption of IgG but not of IgM. The ratio of specific to unspecific binding is optimal after an incubation period of $20 \mathrm{~min}$ for the test serum.

Optimal conditions for specific binding of enzyme-labeled reagents. For the detection of Sendai virus antibodies of all immunoglobulin classes, we used HRPO-labeled SV. To differentiate murine IgG from IgM antibodies 


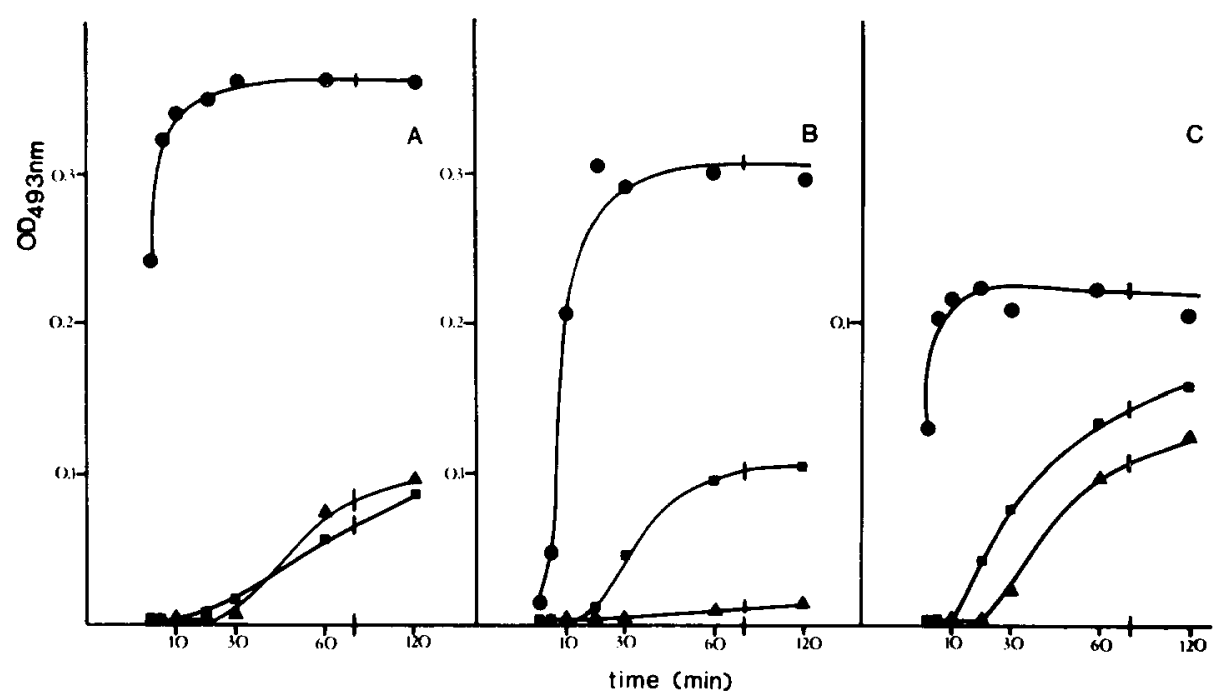

Fig. 3. Kinetics of specific and non-specific binding of mouse immunoglobulin. Wells were coated with SV or buffer. Incubation of antisera was stopped after different intervals. $(\bullet)$ anti-SV serum No. $13.1(1: 100)$, incubated in wells coated with SV;

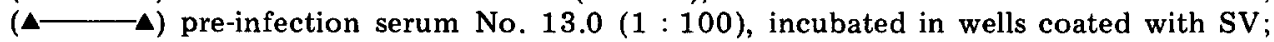
(- $\longrightarrow$ ) anti-SV serum No. 13.1 (1: 100), incubated in wells treated with buffer. HRPO-labeled RAM/Ig (A), RAM/IgG (B) and RAM/IgM (C) were used as conjugate.

HRPO-labeled rabbit anti-mouse-immunoglobulin sera were used. After the conjugation procedure the unbound HRPO had to be removed carefully by ultracentrifugation or gel chromatography as free HRPO tends to adopt nonspecifically to the wells. One of the main problems of antibody detection by radioimmunoassay is non-specific adsorption of ${ }^{125}$ I-labeled antibodies or antigen to the test wells. Surprisingly, with HRPO-labeled antibodies or anti: gens non-specific binding is much slower than with unlabeled or ${ }^{125} \mathrm{I}$-labeled proteins. By use of a short incubation time (20-30 min) non-specific staining of negative controls may be completely avoided. After 60 min nonspecific binding of conjugates increases rapidly. The intensity of staining with positive sera depends on the concentration of conjugate added to the wells. High concentrations of enzyme-labeled SV or RAM/Ig give strong staining of positive wells after addition of substrate, but unfortunately also causes staining of negative controls, so that weak antibodies or antibodies at high dilutions are no longer distinguishable from negative controls. 50-100 ng SV-HRPO or $100 \mathrm{ng}$ enzyme-labeled RAM/Ig (RAM/IgG or RAM/IgM) gave sufficient staining of positive wells $(A>0.5)$ and optimal ratios of specific to unspecific binding ( $>50)$.

Specificity of the assay. Virus grown in the chorioallantoic cavity of embryonated chicken eggs contains the carbohydrate moiety derived from the host cell (White, 1974). Antibody formation was studied in mice 


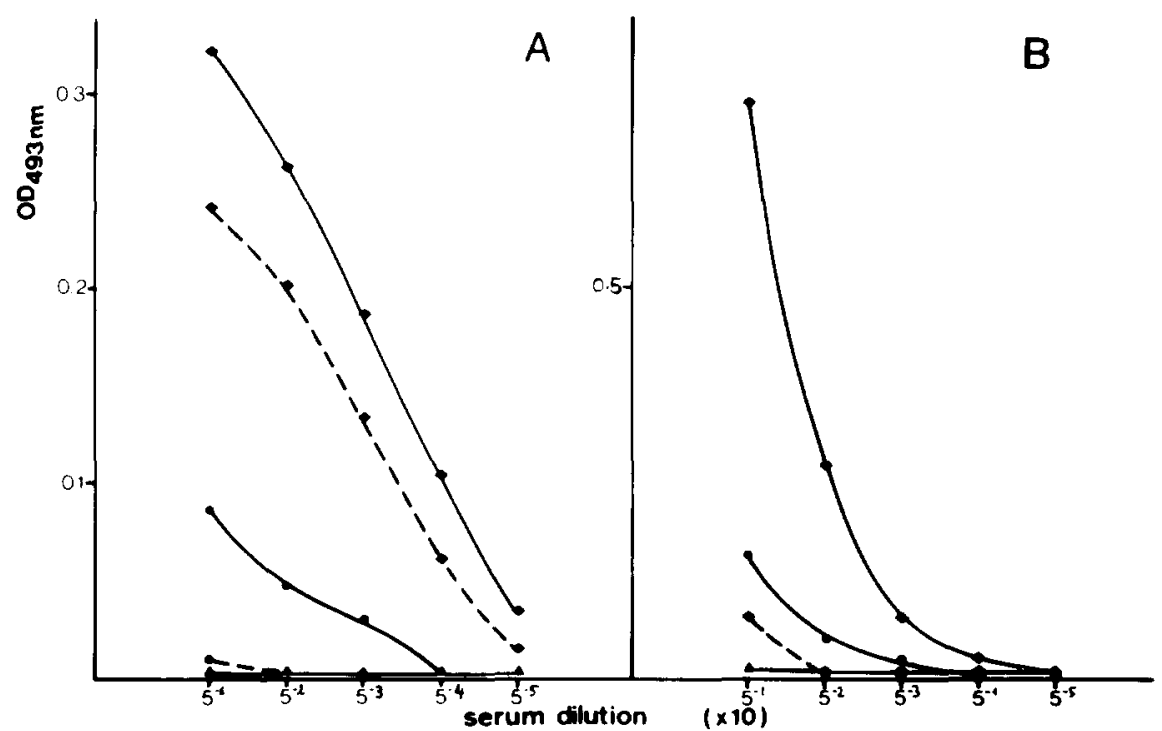

Fig. 4. Blocking of ChHC antibodies. Wells were coated at solid phase with SV (A) or a $1: 10$ dilution of $\mathrm{CF}(\mathrm{B})$. Antisera were added for $30 \mathrm{~min}$ at room temperature. ( $) \mathrm{SV}$ antiserum No. $13.1 ;(\bullet)$ Influenza virus antiserum; (৫) preserum No. 13.0. (Pre-infection serum showed no activity and is omitted for the sake of clarity.) After 3-fold rinsing wells were treated for $2 \mathrm{~h}$ with buffer (- $(-)$, or CF $(1: 5)(\cdots$.$) . SV-HRPO was used as$ conjugate.

infected with egg-grown virus and the same virus was used, after purification, for coating or also for conjugation. Therefore this assay detects not only Sendai virus antibodies but also antibodies directed against chicken host components (ChHC). By this mechanis, high crossreactivity with sera directed against other egg-grown viruses such as influenza is found. Sera from virus-primed mice bind to wells coated either with Sendai virus or ChHC (Fig. 4). By addition of excess chorioallantoic fluid, antibodies directed against $\mathrm{ChHC}$ are saturated and are no longer stained by SV-HRPO as is shown by negative results with wells coated with ChHC (Fig. 4B) while specific binding for viral antigen remains positive (Fig. 4A). The activity of Sendai virus antisera was reduced by $25 \%$ to $30 \%$, indicating that $25 \%$ to $30 \%$ of the antibodies are directed against ChHC. A similar percentage is found after sensitizing mice to influenza virus A (Gerhard et al., 1975). The percentage of antibody directed against $\mathrm{ChHC}$ depends on the virus preparation used for sensitization and on the application route. Injection of large amounts of inactivated virus results in a higher fraction of ChHC antibodies than infection with a small amount of infective virus. Antisera produced by intranasal infection show no crossreactivity with ChHC (data not shown). The blocking of anti-ChHC specificity of bound antibodies with chorioallantoic fluid is only effective when SV-HRPO is used as the labeled reagent. In 


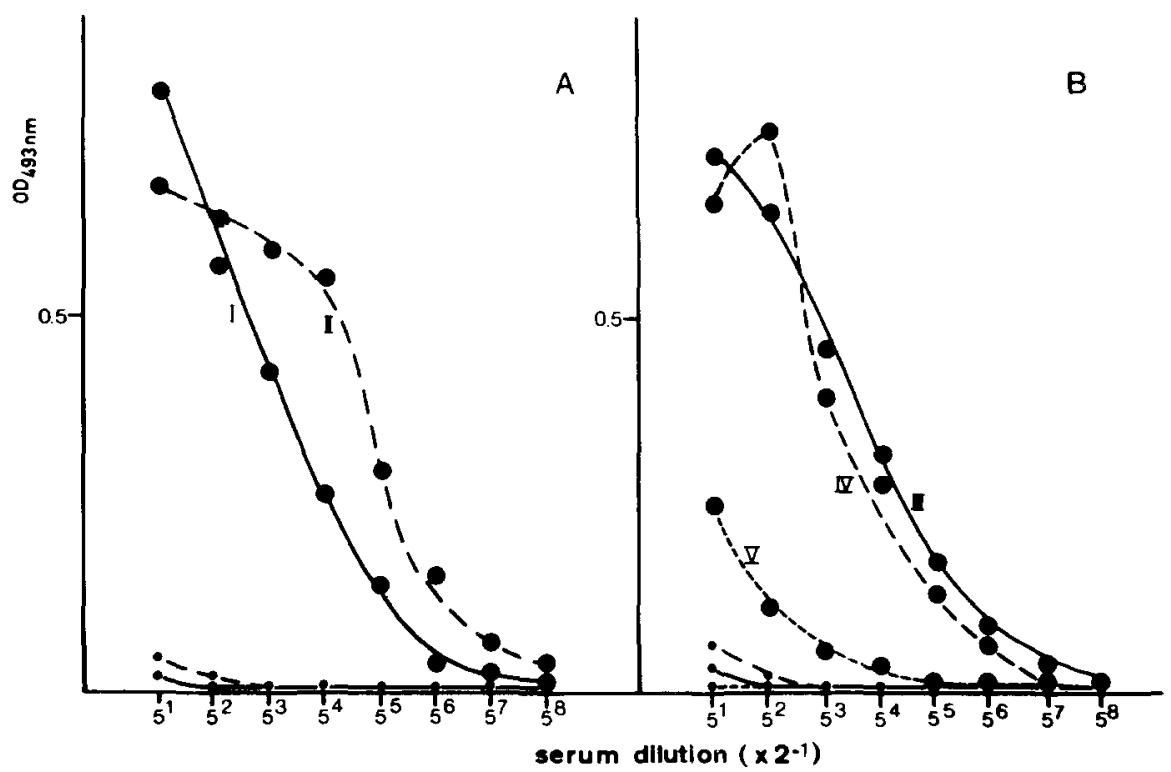

Fig. 5. Sensitivity of different test procedures for the measurement of SV antibodies. Wells were coated with SV, with exception of procedure AII, for which RAM/IgM was used. Dilutions of SV antiserum No. 13.1 (๑) and corresponding pre-infection serum (•) were added for $30 \mathrm{~min}$ at room temperature. SV.HRPO was the labeled reagent for figure A. In figure B HRPO labeled antibodies against immunoglobulins were used (III RAM/Ig, IV RAM/IgG, V RAM/IgM).

assays where enzyme-labeled RAM/Ig preparations were used, test sera were routinely preabsorbed three times for $15 \mathrm{~min}$ at room temperature on wells coated with chorioallantoic fluid.

Crossreactivities with sera directed to other viruses such as rubella or vaccinia were not observed (data not shown).

Sensitivity of the assay. A SV-hyperimmune serum was titrated by several modifications of ELISA as shown in Fig. 5. For demonstration of the total amount of SV antibodies two methods were used. Curve I shows the results with wells coated with SV and SV-HRPO as enzyme-labeled reagent, while in curve III enzyme-labeled RAM/Ig was used. Both methods are equivalent in sensitivity, detecting SV antibodies (serum No. 13.2) to a dilution of about $1: 75.000$. The serum has a titer of $1: 2560$ in HIA.

Two methods were used to demonstrate IgM antibodies. In the first, wells were coated with RAM/IgM (Fig. 5, curve II), total IgM was then bound to the solid phase and SV specific IgM was detected by SV-HRPO. In the second procedure (Fig. 5, curve V) SV was used as solid phase reagent, SV antibodies were bound irrespective of Ig class and demonstration of IgM was by enzyme-labeled RAM/IgM. The first procedure was superior in sensitivity to the second. Selective determination of anti-SV IgG was done by enzymelabeled RAM/IgG (Fig. 5, curve IV). 
High concentrations of preinfection serum were non-specifically stained especially if RAM/IgG was used as enzyme reagent.

In our experiment (Fig. 5) we used an antiserum from DBA/2 mice, which was produced by three injections of $100 \mathrm{HAU}$ of $\mathrm{SV}$ at weekly intervals. Mice were bled one week after the last injection.

\section{Application of the assay}

Early antibody synthesis. Infection of mice with $100 \mathrm{HAU}$ of Sendai virus using different application routes (intraperitoneal, intravenous, intranasal or subcutaneous) resulted in all cases in good antibody production after 2 to 4 days (Fig. 6). Infection by i.p., i.n. or s.c. injection gave comparable amounts and time courses of antibody production, while after i.v. infection antibodies increased earlier and reached, especially in the case of IgM, higher levels. HIA gave low, if any, demonstrable titers during the first week.

Propagation of SV in mice is not necessary to provide powerful stimulus for antibody production. I.p. injection of a high dose of $\beta$-propiolactone
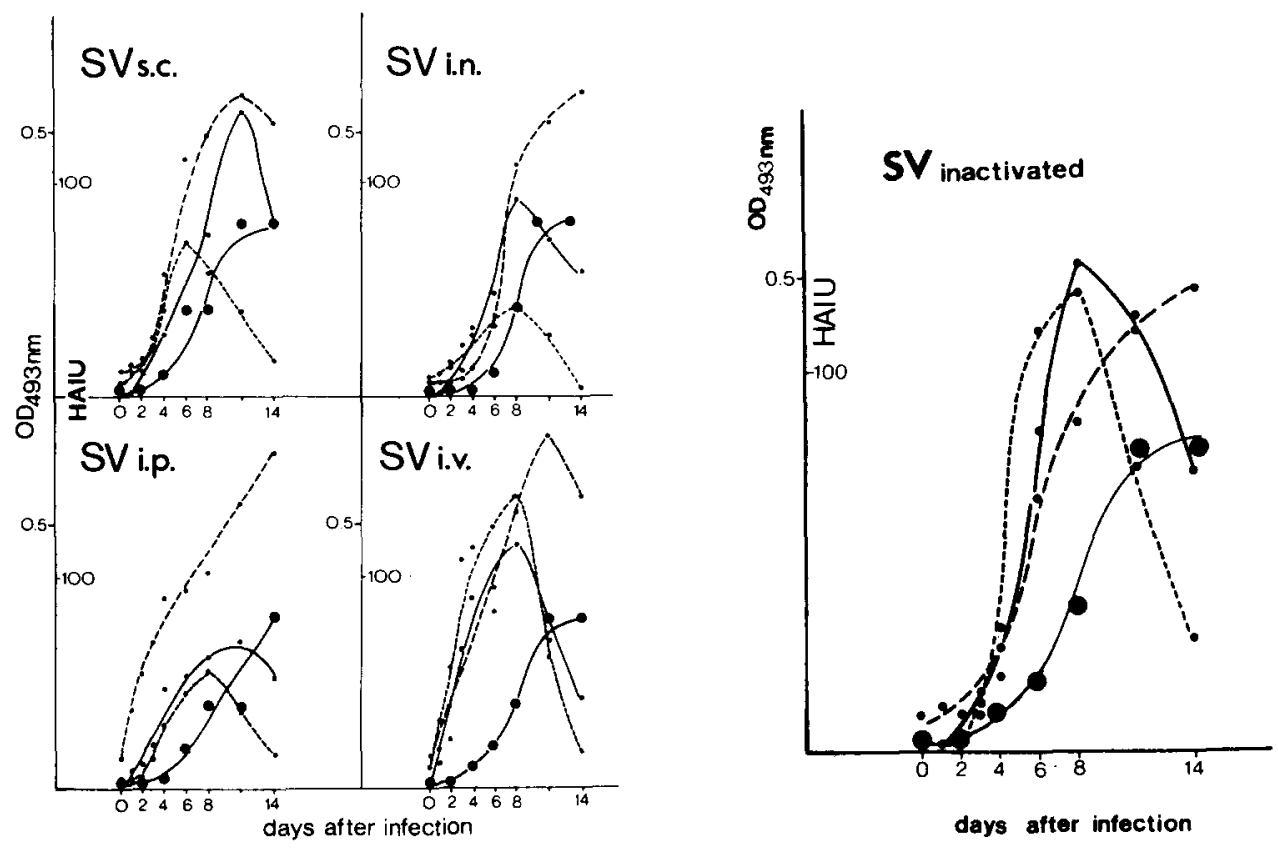

Fig. 6. Influence of application route on antibody formation: Sera, which were pooled from three mice, were obtained at different intervals after i.p., i.v., s.c. and i.n. injection of SV and tested in a dilution of $1: 100$. Total SV antibody ( $\longrightarrow$ ) was demonstrated by procedure I (Fig. 5), SV-IgM ( . . . $\bullet$ ) by procedure II and SV-IgG by pro. cedure IV $(\bullet-\longrightarrow)$. Titers in HIA were also determined $(\bullet-\bullet)$ ).

Fig. 7. Antibody formation after i.p. injection of inactivated SV: See legend of Fig. 6. Serum was obtained after i.p. injection of $500 \mathrm{ng}$ of $\beta$-propiolactone inactivated SV. 
inactivated virus $(0.5 \mu \mathrm{g} /$ mouse $)$ caused antibody production on a similar scale to that after injection of infective virus (Fig. 7). Production of specific IgM was if anything slightly increased.

Antibody production in vitro. In the Sendai virus system it is possible to stimulate cytolytic T-lymphocytes in a primary in vitro induction phase (Koszinowski, unpublished results). It was not known whether specific antibodies are also produced in these cultures. Freeze-dried supernatants $(25 \mathrm{ml})$ of primary induction phase cultures were collected and diluted in $1 \mathrm{ml}$ $0.02 \mathrm{M}$ phosphate buffer, $\mathrm{pH}$ 7.4. Total Sendai virus antibodies and IgM antibodies against SV were determined. As seen in Fig. 8, spleen lymphocytes cultured in the presence of SV produced antibodies to SV. In comparison with the in vivo production of Sendai virus antibodies by DBA/2 mice in one week (Fig. 8B), antibody content of the in vitro cultures was rather low. This may be due to the formation of immune complexes with the large amount of Sendai virus $(2.5 \mu \mathrm{g})$ per culture or to the short duration of antibody production ( 2 days after removal of medium, containing fetal calf serum).

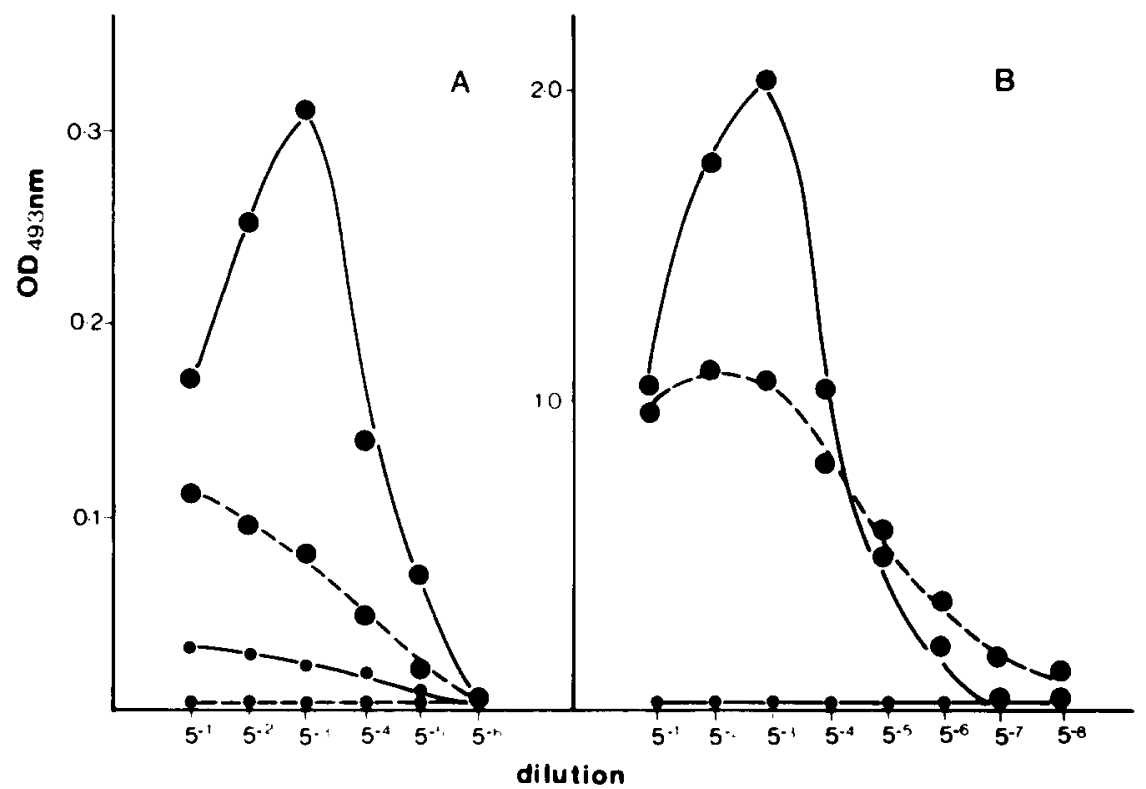

Fig. 8. A: titration of SV-antibodies produced in vitro. Total SV-antibody $(\longrightarrow$ ) or SV-IgM $(--)$ were determined in supernatants of DBA/2 lymphocytes previously cultured in the presence $(\bullet)$ or absence $(\bullet)$ of SV. B: titration of SV-antibodies in the serum of DBA/2 mice one week after infection with SV $(\bullet)$ and test results for the corresponding pre-infection serum $(\bullet)$. 


\section{DISCUSSION}

This report describes an enzyme-linked immunosorbent assay (ELISA) for the demonstration of Sendai virus antibodies. The main advantages of ELISA are greater sensitivity in comparison with standard assays and the possibility of differentiating between immunoglobulins of the IgG and IgM class (Leinikki and Passila, 1977). In routine procedures antibodies to paramyxoviruses are determined by hemagglutination inhibition assay or by complement fixation. Titers demonstrable by these methods rarely exceed $1: 200-$ 1 : 500 and often change from one test to the next. To prove a primary infection IgG and IgM have to be separated by ultracentrifugation.

The enzyme-linked immunosorbent assay is about 20 -fold more sensitive than the hemagglutination inhibition assay; it detects other (and more) antigenic determinants, and it is not influenced by non-specific inhibitors which often confuse the results of HIA. Virus neutralisation tests are very sensitive and detect low levels of antibodies at an early stage of infection (Svenag and Mandel, 1964) but are too laborious for routine work, while results are often non-specific because of the influence of interferon. The sensitivity of ELISA is comparable with that of RIA (Ertl, unpublished results). ELISA has several advantages over RIA. The chloramine $\mathrm{T}$ method genetically used (Hunter and Greenwood, 1962) causes chemical damage to the antigens of the Sendai virus; for example, hemagglutinin activity is totally destroyed. Enzyme-labeling of the virus is more gentle and hemagglutinin activity is only slightly reduced. Also, enzyme conjugates are more stable than iodinated proteins. Other advantages claimed for such forms of non-radioactive labeled tracers are the absence of health hazard associated with the labeling procedure and work with radioactive products, and the low cost of both the enzyme required for labeling and the colorimetric equipment used for detection. Estimates of antibody titer can be even made visually. For labeling of antigen and anti-mouse immunoglobulins, horseradish peroxidase was used, because it has the advantages of being easily detectable with high sensitivity by various substrates and also of heing very stable.

Peroxidase may be coupled to proteins by bifunctional reagents such as glutaraldehyde. This is simple to perform but requires availability of amino and/or hydroxyl groups on both the peroxidase and the protein. In many peroxidase preparations a majority of these groups is blocked by allythiocyanate (Ornstein, 1966) so that only a low proportion of reaction sites is available for coupling.

An alternative method of coupling peroxidase to protein is oxidation of the glycoside portion of the enzyme by periodate to form aldehyde groups able to bind to the amino groups of the protein (Nakane, 1975). Unfortunately some peroxidase preparations contain only low amounts of carbohydrates which are necessary for this coupling procedure. In this report a combination of both labeling procedures is used which was found to be highly reliable and reproducible. Final treatment with sodium borohydride 
stabilizes the linkages of glutaraldehyde and glycoside-derived aldehydes to the amino groups.

Five ways of assessing antibodies to Sendai virus are described. The total amount of SV antibodies bound to surface coated SV antigens is demonstrable either by using enzyme-labeled SV or alternatively by the application of enzyme-labeled rabbit anti-mouse Ig. The use of SV-HRPO has the advantage of being applicable for testing SV-antibodies from different species. The use of enzyme-labeled anti-mouse Ig is restricted to one animal species, but one HRPO-labeled reagent can be used for detection of antibodies to various viruses on wells coated with the corresponding antigens. This method has a certain risk of increased non-specific activity but this can be avoided by use of short incubation times.

Differentiation of immunoglobulin classes is possible by the demonstration of SV specific antibodies bound to SV coated wells with an Ig class specific conjugate. However, for the measurement of virus specific IgM the coating of wells with R AM/IgM and quantification with enzyme-labeled SV was found to be superior. The amount of IgM in the serum is much smaller than that of IgG, but the percentage of specific IgM is higher than that of IgG at the early phase of immune reaction. Much of the IgM fixed by antiIgM serum to the solid phase should therefore bind SV-HRPO. On the other hand, if $\mathrm{SV}$ is coated, binding of specific IgM to SV is competitively inhibited by specific IgG so that the amount of IgM detectable by enzyme-labeled anti-IgM is reduced.

In the ELISA test it is desirable to have a highly purified antigen and a system whereby specific binding of the test antibody can be distinguished from non-specific adherence phenomena. Since paramyxoviruses grown in embryonated eggs contain chicken host components even after purification it is particularly important to determine antibodies with specificities for ChHC. Using wells coated with $\mathrm{ChHC}$ we were able to distinguish between antiviral and anti-ChHC activity of the sera. Anti-ChHC activity, which amounted to about $30 \%$ of total antibody activity, could be easily removed by competition with chorioallantoic fluid or by preadsorption of test sera on wells coated with chorioallantoic fluid. Although it is possible to use viral antigens grown in cell cultures in this test (data not shown) the requirement for specificity can be easily fulfilled by egg grown virus. With little effort the assay system can be modified for investigation of antibodies to a particular protein of the virus using purified viral proteins, for example a purified hemagglutinin or a fusion factor, which could be used as coating material or as the peroxidase labeled conjugate.

The main advantage of the assay is its ability to detect low levels of specific IgG or IgM antibodies. After infection of mice by different routes, the kinetics of IgG and IgM antibody formation were studied. Antibody production after inoculation of virus by the i.p., s.c. or i.n. routes showed similar kinetics, while infection by the i.v. route caused earlier onset of antibody formation and higher IgM levels. Sensitization with $\beta$-propiolactone inacti- 
vated SV showed similar results with enhanced IgM production. It is not yet clear which mechanisms are responsible for these differences. Data obtained with the HIA indicate that this test is too insensitive to study early events in antibody formation.

We were able to demonstrate specific antibody formation in the supernatants of cell cultures after 6 days of primary sensitization of lymphocytes with viral antigens in vitro. These antibodies were not demonstrable by HIA at all. In a similar way the assay should help in selecting viral antibody producing hybridomas at an early stage. Use of this assay for analysis of cellular and viral requirements for induction and regulation of antibody formation is in progress.

\section{ACKNOWLEDGEMENTS}

We thank Prof. R. Thomssen for helpful discussion and Mrs. I. Dreyer for her valuable help in the preparation of the manuscript.

\section{REFERENCES}

Avrameas, S. and T. Ternynck, 1971, Immunochemistry 8, 1175.

Bennink, J.R. and P.C. Doherty, 1978, J. Exp. Med. 148, 128.

Doherty, P.C., R.V. Blanden and R.M. Zinkernagel, 1976, Transplant. Rev. $29,89$.

Doherty, P.C., W.E. Biddison, J.R. Bennink and B. B. Knowles, 1978, J. Exp. Med. 148, 534.

Ertl, H. and U. Koszinowski, 1976, Immunobiology 152, 128.

Gerhard, W., T.J. Braciale and N.L. Klinman, 1975, Eur. J. Immunol. 5, 720.

Hunter, W.M. and F.C. Greenwood, 1962, Nature 194, 495.

Koszinowski, U. and R. Thomssen, 1975, Eur. J. Immunol. 5, 245.

Koszinowski, U., H. Ertl, H. Wekerle and R. Thomssen, 1977a, Cold Spr. Harb. Symp. Quant. Biol. 41, 529 .

Koszinowski, U., M.J. Gething and M. Waterfield, 1977b, Nature 267, 160.

Leinikki, P.O. and S. Passila, 1977, J. Infect. Dis. 136, 294.

Lowry, O.H., N.J. Rosenbrough and P.J. Randall, 1951, J. Biol. Chem. 193, 265.

Nakane, R.P., 1975, Ann. N.Y. Acad. Sci. 254, 203.

Ornstein, L., 1966, J. Histochem. Cytochem. 14, 790.

Roberts, I.M., C.C. Bernard, G.N. Vyas and I.R. Mackay, 1975, Nature 254, 606.

Salk, J.E., 1944, J. Immunol. 49, 87.

Svenag, S.E. and B. Mandel, 1964, J. Exp. Med. 119, 1.

White, D.O., 1974, Curr. Top. Microbiol. Immunol. 63, 1. 